\title{
Effect of growth regulators on micropropagation of Rauvolfia serpentina (L.) Benth
}

\author{
Archana Rani*, M. Kumar and Sanjeev Kumar ${ }^{1}$ \\ Department of Agricultural Biotechnology and Molecular Biology, (FBS and H), Rajendra Agricultural University, \\ Pusa-848125 (Bihar), INDIA \\ ${ }^{1}$ Department of Plant Pathology, College of Agriculture, Jawaharlal Nehru Krishi Vishwa Vidyalaya, Jabalpur- 482004 \\ (MP), INDIA \\ *Corresponding author. E-mail: archanarani22oct@gmail.com
}

Received: April 16, 2014; Revised received: August 15, 2014; Accepted: October 19, 2014

\begin{abstract}
An efficient protocol for micropropagation through in vitro culture of Rauvolfia serpentina was standardized. Out of different combination of phytohormone tested, MS media supplemented with $0.5 \mathrm{mg} \mathrm{L}^{-1}$ Indole Acetic Acid + $0.5 \mathrm{mg} \mathrm{L} \mathrm{Nephthalene} \mathrm{acetic} \mathrm{acid} \mathrm{was} \mathrm{found} \mathrm{to} \mathrm{be} \mathrm{finest} \mathrm{for} \mathrm{mean} \mathrm{callus} \mathrm{induction} \mathrm{(62.66 \% )} \mathrm{as} \mathrm{well} \mathrm{as}$ callus mediated shoot regeneration with mean percentage response (56) and number of shoot per culture (5). In direct shoot regeneration, best growth of axillary shoots was obtained on MS media supplemented with $0.5 \mathrm{mg} \mathrm{L}^{-1}$ Indole Acetic Acid + $0.5 \mathrm{mg} \mathrm{L}^{-1}$ Benzyl Amino Purine with maximum mean percentage response(77.33) and number of shoots per culture (9.0), however the best shoot elongation of shoot was found on MS media supplemented with $3.0 \mathrm{mg} \mathrm{L}^{-1}$ IAA plus $3.0 \mathrm{mg} \mathrm{L}^{-1}$ BAP with 6.50 (mean). Higher induction of root (88\%) with mean number of root per culture (12) was observed in MS medium supplemented with Indole Butyric Acid $\left(3.0 \mathrm{mg} \mathrm{L}^{-1}\right)$. The rooted plantlets were successfully established in the field. The protocol was optimized by manipulations of different PGRs for enhanced multiplication. Protocol explained in this research paper provides a rapid plant regeneration system which could be used for production of large number of true to the type, uniform, disease free, elite, plantlets right through the year, which will make things easier for large scale cultivation of this endangered important medicinal plant.
\end{abstract}

Keywords: Growth regulators, Medicinal plant, Micropropagation, Rauvolfia serpentina

\section{INTRODUCTION}

Rauvolfia serpentina (L.) Benth. Ex Kurz. (Apocyaneae) a woody perennial shrub, commonly known as 'Sarpgandha' is an endangered medicinal plant found in Bangladesh, China, Indonesia, India, Malaysia, Nepal, Pakistan, Sri Lanka and Viet Nam (Dey and De, 2010; and Sushila et al., 2013). The roots of this shrub have been used for centuries in ayurvedic medicines. Root are bitter, acrid, laxative, thermogenic, diuretic and possess sedative properties. This herbal plant is used as medicine for high blood pressure, insomnia, anxiety and other disorders of the central epilepsy. It is highly reputed for hypertension and is useful in stangury, fever, wounds, insomnia, epilepsy and dyspepsia, remedy for the removal of opacities of the cornea, increase uterine contractions and anthelmintic and antidote to snake venom (Prakash, 2001; Jain et al., 2003 and Pawar et al., 2011).

Reserpine is a potent indole alkaloid first isolated from this plant which is being widely used as an antihypertensive (Anonymous, 2003). Due to poor seed germination rate, large scale and indiscriminate collection of wild plants for pharmaceutical purposes and insufficient attempts to either allow its replenishment or its cultivation, $R$. serpentina is rapidly disappearing and is now listed as an endangered species by the International Union for Conservation of Nature and Natural Resources (IUCN) (Jain et al., 2003; Singh et al., 2009; Sushila et al., 2013). The propagation of $R$. serpentina through seeds is difficult due to less viability and very low germination percentage $(25 \%-50 \%)$ and is often as low as 10 percent that is due to the presence of cinnamic acid derivatives (Mitra, 1976; Mallik et al., 2012). In vitro culture is an alternative method for conservation and propagation of this species. Propagation of $R$. serpentina through tissue culture has previously been described but most of them have focused on micro propagation by means of stimulating auxiliary shoot from shoot tip as explants (Singh, 2009; Harisaranraj, 2010 and Rani et al., 2013). However, detailed holistic study on in vitro regeneration of $R$. serpentina in Bihar is lacking. Therefore, this study was aimed at development of an efficient protocol for micropropagation of $R$. serpentina by optimizing growth regulators such as auxin and cytokinins. 


\section{MATERIALS AND METHODS}

Plant material:. The shoots of about $1.5-2 \mathrm{~cm}$ long were collected from the experimental garden of Department of Agricultural Biotechnology and Molecular Biology at RAU, Pusa (Bihar) for in vitro studies in year 2009-2010. The explants were first washed with running tap water for $20 \mathrm{~min}$., soaked in $70 \%$ (v/v) ethanol for $1 \mathrm{~min}$., surface sterilized with Tween-20 (6 drop $\left.\mathrm{L}^{-1}\right)$ for $20 \mathrm{~min}$. and rinsed in sterile distilled water thrice. The explants were then treated with $0.1 \% \mathrm{HgCl}_{2}$ for $2 \mathrm{~min}$. and washed with sterile distilled water in laminar air flow chamber.

Culture medium and culture conditions: The explant was then inoculated in the appropriate MS medium (Murashige and Skoog, 1962), which contained sucrose (3\%), and $\mathrm{pH}$ (5.8). Cutting edge of the explants was kept in direct contact with the medium. The cultures were incubated at $24 \pm 2^{\circ} \mathrm{C}$ under 2000 lux light intensity using white fluorescent lamp for $16 \mathrm{hr}$ photoperiod. The basal MS medium was used with derived supplementation of phyto-regulators for the induction of shoots and roots. The MS basal media supplemented with different auxins such as The MS basal media supplemented with different auxins: Indole Butyric acid (IBA) 0.5, 1.0, 1.5, 2.0, $3.0 \mathrm{mgL}^{-1}$, Indole Acetic acid (IAA) 0.5. 1.0, 2.0, $3.0 \mathrm{mg} \mathrm{L}^{-1}$ and Naphthalene Acetic Acid (NAA) 0.5, 1.0, 1.5, $2.0 \mathrm{mgL}^{-1}$ and cytokinin: Benzyl Amino Purine (BAP) 0.5, 1.0, 1.5, 2.0, $3.0 \mathrm{mgL}^{-1}$ and Kinetin (KIN) $0.5,1.0 \mathrm{mg} \mathrm{L}^{-1}$. At this culturing stage, various types and concentrations of plant growth regulators (PGRs) were evaluated for callusing, shoot proliferation and root formation.

Acclimatization: The rooted shoots were removed from the culture tube and washed with sterile water to the remove any traces of agar on the roots and dipped in $0.2 \%(\mathrm{w} / \mathrm{v})$ carbendazim $50 \mathrm{WP}$ (Bavistin) solution for $20 \mathrm{~min}$. Plantlets were transferred to plastic pots filled with sterile soil and kept in green house. Initially, the pots were covered with polybags and after 25 days these were uncovered and shifted gradually from shade to sunlight.

Statistical analysis: Each in vitro experiment was conducted in completely randomized design and each treatment replicated thrice with 20 explants per treatment. The frequency of callogenesis, shoot formation on callus, direct shoot formation and root regeneration per culture were determined upto 50 days after inoculating explants on different media. The data was analyzed by using the OPSTAT statistical package software.

\section{RESULTS AND DISCUSSION}

Callogenesis: Aseptic shoot apex explants of R. serpentina were cultured aseptically under in vitro condition. After a week, callus induction and proliferation were obtained by inoculating sterile shoot apex only on MS medium containing 3.0\% sucrose $(\mathrm{w} / \mathrm{v})$ which supplemented with different concentrations of BAP $\left(0.5,1.0,1.5 \mathrm{mg} \mathrm{L}^{-1}\right)$ with $\mathrm{KIN}\left(0.5,1.0 \mathrm{mg} \mathrm{L}^{-1}\right)$ or NAA $\left(0.5,1.0 \mathrm{mg} \mathrm{L}^{-1}\right)$. The rate of callus formation was slow in the first two weeks. However, callus exhibited good growth and covered the whole explant within $3-4$ weeks. Shoot primordia also developed on the callus, which exposed its organogenic nature. The major portion of the callus was soft friable and creamy white. Out of different combination of phytohormone tested, $0.5 \mathrm{mg} \mathrm{L}^{-1} \mathrm{NAA}+0.5 \mathrm{mg} \mathrm{L}^{-1} \mathrm{BAP}$ was found to be best for mean callus induction (62.66) percentage and days to callus induction (Plate 1). The combination showed $53 \%$ response with respect to the callus induction in shoot apex in 28 days. The callus induction gradually reduces with increased concentration of BAP (Table 1). Adhikari and Pant (2013) reported that the best callusing were observed on MS media supplemented with BAP $0.5 \mathrm{mg} \mathrm{L}^{-1}+\mathrm{NAA} 1.5 \mathrm{mg} \mathrm{L}^{-1}$ in W.somnifera. Mallik et. al., 2012 obtained good callus
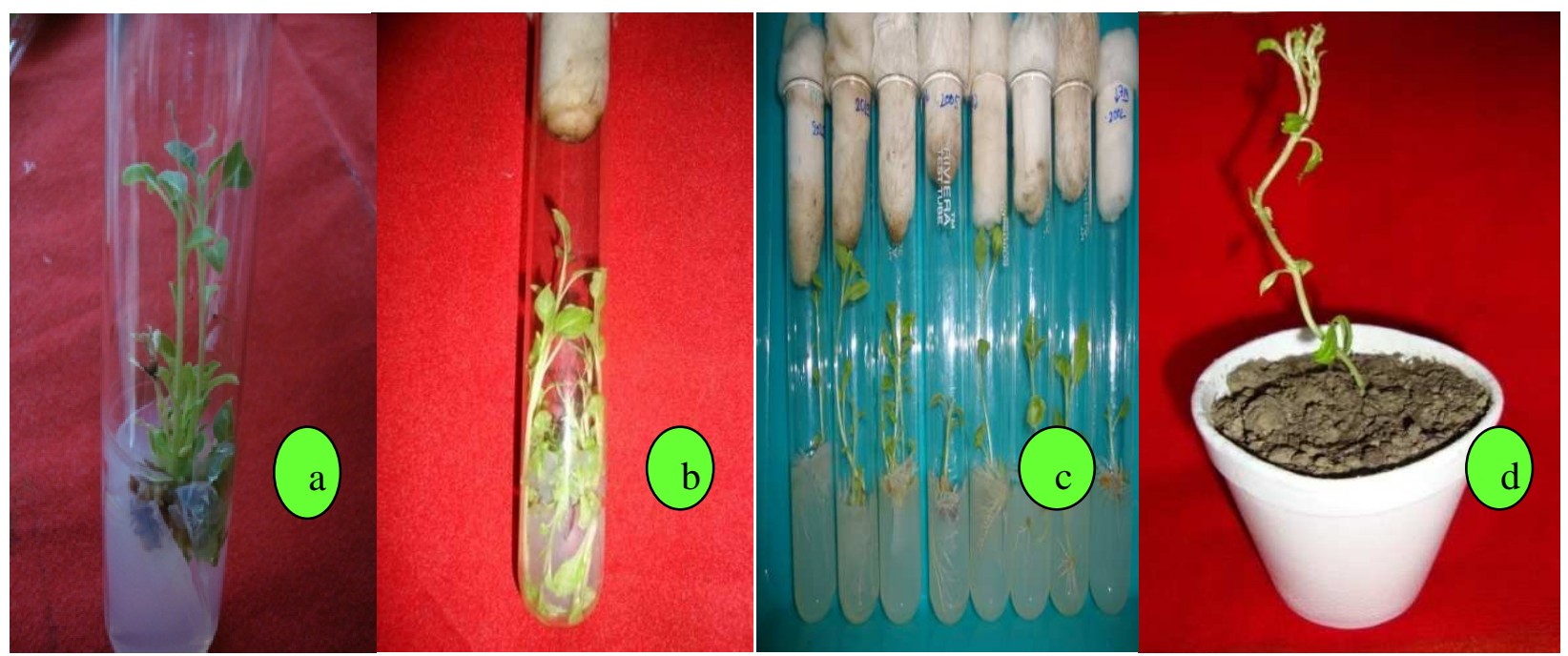

Plates 1. In vitro responses from shoot apex in genotype RS-1 of R. serpentina (a) Callus mediated shoot induction; (b) Direct shoots proliferation; (c) Rooting of regenerated shoots; (d) Regenerated plantlets in pot. 
growth on MS medium on Rauwolfia serpentina stem explants using a combination of BAP $\left(1.0-2.5 \mathrm{mg} \mathrm{L}^{-1}\right)$ and IAA $\left(0.1-0.2 \mathrm{mg} \mathrm{L}^{-1}\right)$ which is contrary to our result. We did not get callus on MS media on shoot apex explants using a combination of BAP $(0.5,1.0$, $2.0,3.0)$ and $\operatorname{IAA}(0.5,1.0,2.0,3.0)$. However, poor growth of callus is observed on MS media on shoot apex explants using a combination of $\operatorname{BAP}(0.5,1.0)$ and $\operatorname{KIN}(0.5,1.0)$.

Shoot regeneration on callus: The callus derived from shoot apex explants produce multiple shoots after 2-4 weeks of culture in basal MS medium which supplemented with different concentrations of BAP $\left(0.5,1.0,1.5 \mathrm{mg} \mathrm{L}^{-1}\right)$ with $\mathrm{KIN}\left(0.5,1.0 \mathrm{mg} \mathrm{L}^{-1}\right)$ or NAA $\left(0.5,1.0 \mathrm{mg} \mathrm{L}^{-1}\right)$. Callus mediated shoot proliferation and elongation were observed on MS medium supplemented with varying concentrations of BAP or KIN (Table 1). At higher concentrations of BAP or KIN, the growth and no. of the shoots per culture was lower (Plate 1a). The MS Medium containing BAP $\left(0.5 \mathrm{mg} \mathrm{L}^{-1}\right)$ plus $\mathrm{KIN}\left(0.5 \mathrm{mg} \mathrm{L}^{-1}\right)$ was observed as the most effective combination for callus mediated shoot induction resulted better mean number of shoots per culture (4.0) with mean shoot length $(3.0 \mathrm{~cm})$. Panwar et al. (2011) reported that at higher concentration of BAP the number of shoots per culture declined gradually in the callus derived from leaf explants of $R$. serpentina as found in our result. Harisaranraj et al. ( 2011) reported that at higher concentration of either NAA or BAP in the culture MS medium inhibited the growth of the shoots and stimulated small callusing at the basal end of $R$. serpentina as in our observation (Table 1, Plate-1). The number of multiple shoots per explants varied from 2.00 to 5.00 between treatments with percentage response (16-73). Edson et al., 1996 reported that minimal cytokinins and auxins in culture media would avoid somaclonal variation and efficiently produce true to type plantlets.

Direct shoot regeneration: The in vitro multiplication of $R$. serpentina shoots through the sprouting of axillary buds is the most commercially viable means of micropropagation. The initial response of axillary shoot buds formation was observed after 2-3 weeks of culturing of shoot apex explant (Table 1). Out of the fourteen combinations of shoot induction media tested, direct shoot regeneration was obtained only on seven MS media which contained different concentrations of IAA and BAP.A progressive degree of percentage response and no. of axillary shoot bud per culture were observed with decrease the concentration of IAA with BAP while, at higher concentrations led to increase in shoot elongation. The maximum mean number of shoots per culture (9.00) and mean percentage response $(77.33 \mathrm{~cm})$ was obtained on MS media supplemented with $0.5 \mathrm{mg} \mathrm{L}^{-1}$ IAA plus $0.5 \mathrm{mg} \mathrm{L}^{-1}$ BAP. (Table 1, Plate 1(b). The best response of axillary shoot bud elongation was observed with

Table 1. In vitro response from shoot apex explants of $R$. serpentina cultured on different compositions of (IAA, NAA, BAP and KIN) MS media.

\begin{tabular}{|c|c|c|c|c|c|c|c|c|}
\hline \multicolumn{4}{|c|}{$\begin{array}{l}\text { Phytohormone in } \\
\left(\mathrm{mg} \mathrm{L}^{-1}\right)\end{array}$} & \multirow[t]{2}{*}{$\begin{array}{c}\text { Response } \\
(\%)\end{array}$} & \multirow{2}{*}{$\begin{array}{c}\text { Mean No. of } \\
\text { shoots/culture } \\
(\text { Mean } \pm \text { SE })\end{array}$} & \multirow{2}{*}{$\begin{array}{l}\text { Mean length } \\
\text { of shoot in } \mathrm{cm} \\
(\text { Mean } \pm \text { SE })\end{array}$} & \multirow{2}{*}{$\begin{array}{c}\text { Mean } \\
\text { induction } \\
\text { of callus } \\
(\text { Mean } \pm S) \\
\end{array}$} & \multirow[t]{2}{*}{$\begin{array}{c}\text { Nature of } \\
\text { callus }\end{array}$} \\
\hline IAA & BAP & KIN & NAA & & & & & \\
\hline & 0.5 & 0.5 & & $52.66 \pm 0.88$ & $4.00 \pm 0.57$ & $3.00 \pm 0.57$ & $37.66 \pm 1.45$ & $\mathrm{~F}, \mathrm{~W}$ \\
\hline & 1.0 & 0.5 & & $59.00 \pm 1.15$ & $3.00 \pm 0.57$ & $1.00 \pm 0.28$ & $26.66 \pm 0.88$ & SF,W \\
\hline & 1.0 & 1.0 & & $56.00 \pm 0.57$ & $3.66 \pm 0.33$ & $0.70 \pm 0.05$ & $13.00 \pm 1.00$ & SF,W \\
\hline & 0.5 & & 0.5 & $56.00 \pm 1.15$ & $5.00 \pm 1.15$ & $2.50 \pm 0.76$ & $62.66 \pm 1.45$ & SF,W \\
\hline & 0.5 & & 1.0 & $16.00 \pm 0.57$ & $4.33 \pm 1.20$ & $3.66 \pm 1.20$ & $53.00 \pm 1.73$ & SF,W \\
\hline & 1.0 & & 1.0 & $36.66 \pm 0.88$ & $2.00 \pm 0.57$ & $2.66 \pm 0.88$ & $43.66 \pm 1.66$ & $\mathrm{SF}, \mathrm{W}$ \\
\hline & 1.5 & & 0.5 & $73.00 \pm 1.15$ & $2.33 \pm 0.33$ & $3.33 \pm 0.66$ & $25.33 \pm 1.45$ & SF,W \\
\hline 0.5 & 0.5 & & & $77.33 \pm 1.20$ & $9.00 \pm 0.57$ & $3.33 \pm 0.33$ & - & - \\
\hline 1.0 & 1.0 & & & $46.66 \pm 0.88$ & $6.00 \pm 0.57$ & $4.66 \pm 0.33$ & - & - \\
\hline 1.0 & 2.0 & & & $53.66 \pm 0.33$ & $4.33 \pm 0.33$ & $4.66 \pm 0.66$ & - & - \\
\hline 2.0 & 3.0 & & & $47.33 \pm 0.88$ & $2.33 \pm 0.33$ & $5.00 \pm 0.57$ & - & - \\
\hline 3.0 & 1.0 & & & $13.33 \pm 0.88$ & $2.66 \pm 0.66$ & $6.43 \pm 0.29$ & - & - \\
\hline 3.0 & 2.0 & & & $24.66 \pm 1.45$ & $4.66 \pm 0.33$ & $5.70 \pm 0.17$ & - & - \\
\hline 3.0 & 3.0 & & & $27.00 \pm 0.57$ & $3.00 \pm 0.57$ & $6.50 \pm 0.36$ & - & - \\
\hline \multicolumn{3}{|c|}{ C.D. $(p \leq 0.05)$} & & 2.75 & 1.87 & 1.72 & 2.90 & \\
\hline \multicolumn{3}{|c|}{ S.E.(m) } & & 0.94 & 0.64 & 0.59 & 0.99 & \\
\hline
\end{tabular}

Visual observation; callus - = no response; $\mathrm{W}=$ white; $\mathrm{F}=$ friable; $\mathrm{SF}=$ semifriable 
Table 2. In vitro response from regenerated shoots explants of $R$. serpentina subcultured on different compositions of (IBA and NAA) MS media for rooting.

\begin{tabular}{|c|c|c|c|}
\hline $\begin{array}{l}\text { Phyto hormone in } \\
\left(\text { (mg L L }^{-1}\right) \\
\text { IBA NAA }\end{array}$ & $\begin{array}{c}\text { Response } \\
(\%)\end{array}$ & $\begin{array}{c}\text { Mean No. of } \\
\text { root/shoots }(\text { Mean } \pm \text { SE) }\end{array}$ & $\begin{array}{l}\text { Mean length of root } \\
\text { in cm }(\text { Mean } \pm S E)\end{array}$ \\
\hline 0.5 & $73.00 \pm 3.00$ & $7.33 \pm 1.76$ & $4.46 \pm 0.88$ \\
\hline 1.0 & $74.00 \pm 3.05$ & $3.33 \pm 0.66$ & $3.66 \pm 0.88$ \\
\hline 1.5 & $75.66 \pm 2.18$ & $3.33 \pm 0.88$ & $3.66 \pm 0.33$ \\
\hline 2.0 & $71.66 \pm 3.28$ & $2.66 \pm 0.88$ & $2.00 \pm 0.57$ \\
\hline 3.0 & $88.00 \pm 1.52$ & $12.00 \pm 1.73$ & $6.33 \pm 0.33$ \\
\hline 0.5 & $84.66 \pm 1.45$ & $8.66 \pm 1.85$ & $6.00 \pm 1.15$ \\
\hline 1.0 & $84.66 \pm 2.60$ & $11.33 \pm 3.52$ & $3.33 \pm 0.66$ \\
\hline 1.5 & $87.66 \pm 1.76$ & $5.00 \pm 1.15$ & $2.66 \pm 0.66$ \\
\hline 2.0 & $87.66 \pm 1.20$ & $3.66 \pm 1.45$ & $1.66 \pm 0.33$ \\
\hline C.D. $(p \leq 0.05)$ & 7.03 & 5.22 & 2.10 \\
\hline S.E.(m) & 2.349 & 1.74 & 0.70 \\
\hline
\end{tabular}

6.50(mean) on MS media supplemented with $3.0 \mathrm{mg}$ $\mathrm{L}^{-1}$ IAA plus $3.0 \mathrm{mg} \mathrm{L}^{-1} \mathrm{BAP}$. Thus, the propagation of plants from axillary buds has proved to be the most generally applicable and reliable method of in vitro propagation in $R$. serpentina, as the regeneration of the plant is very difficult from seeds and other sources. The seeds are mostly non-viable due to abortive embryos (Mitra, 1976; Akram and Illahi,1986). Harisaranraj et al. (2010) reported that the growth of the shoots was stunted with increase in the frequency of concentrations of BAP, NAA or KIN in $R$. serpentina which is in consent with present result.

Root regeneration and acclimatization: Rooting ability of in vitro regenerated shoots in the present studies was satisfactory. In vitro regenerated shoots produced profuse rooting after 15-20 days of sub culturing on MS medium supplemented with various concentrations of NAA or IBA. Out of different hormone concentration of MS media tested, IBA (3.0 $\mathrm{mg} \mathrm{L}^{-1}$ ) was found to be best for root induction percentage $(88 \%)$, mean number of root per explant (12) and mean root length $(6.33 \mathrm{~cm})$ followed by NAA(1.0 $\left.\mathrm{mg} \mathrm{L}^{-1}\right)$ with root induction percentage $(84.66 \%)$, mean number of root per explant (11.33) and mean root length $(3.3 \mathrm{~cm})$. The roots were long, pale white, robust with root hairs (Table 2). Plate 1 (c).The present result is in accordance with the result reported by Rahman et al.2008. They reported that the adventitious shoots were best rooted on half strength MS medium supplemented with $1.0 \mathrm{mg} \mathrm{L}^{-1}$ of IBA. NAA and IBA has been reported to have a stimulatory effect on root induction in many tree species (Channd,1995). Susila et al.( 2013) got 100\% rooting when transferred in vitro regenerated multiple shoots of $R$. serpentina on half-strength MS medium supplemented with NAA $\left(0.2 \mathrm{mg} \mathrm{L}^{-1}\right)$ plus IBA $(0.2$ $\left.\mathrm{mg} \mathrm{L}^{-1}\right)$. Finally, the developed plantlets were kept in poly-house and greenhouse for hardening, and then transferred to field. About $70 \%$ of the plants transferred to field survived and did not show any detectable variation in morphology or growth characteristics when compared to the mother plants (Plate1e).

In conclusion, an efficient protocol for micropropagation of an important medicinal plant, $R$. serpentina, was developed in this study by testing various concentrations of growth regulators and culture conditions. This method produces a large number of true to the type, uniform, disease free, elite, plantlets right through the year, which will make things easier for large scale cultivation of this endangered important medicinal plant for commercial extraction of alkaloid for therapeutic use. This can lead to the synthesis and extraction of active compounds from its root.

\section{REFERENCES}

Adhikari, S. R. and Pant, B. (2013). Induction and proliferation of in vitro mass of callus of Withania somnifera (L.) Dunal. Research in Plant Sciences, 1(3):58-61.

Akram, M. and Illahi, I.(1986). Plantlets formation in root callus of Rauwolfia serpentine. Pakistan Journal of Botany, 18:15-19.

Anonymous (2003). The wealth of India: A Dictionary of Indian Raw Materials and Industrial Products. CSIR, New Delhi, India.

Channd, P. K., Sahoo,Y., Pattnaik, S. K. and Patnaik, S. N. (1995). In Vitro Meristem culture - an efficient ex situ conservation strategy for elite mulberry germplasm. In: R. C. Mohanty, Ed., Environment Change and Management, Kamla Raj Enterprises, New Delhi.,127133.

Dey A. and De, J. N. (2010). Ethnobotanical aspects of Rauvolfia serpentina (L). Benth. ex Kurz. in India, Nepal and Bangladesh. J. Med. Plant Res., 5: 144-150.

Edson, J. L., Leege-Brusven, A. D., Everett, R. L. and Wenny, D.L.(1996).Minimizing growth regulators in shoot culture of an endangered plant, Hackelia ventusa (Boraginaceae). In Vitro Cell Dev Biol. Plant, 32: 267271. 
Harisaranraj, R., Suresh, K. and Saravana, Babu, S.(2010). Effect of growth regulators on micropropagation of Rauvolfia Serpentina (L.) Benth. Research Journal of Biotechnology, 5 (2):52-55.

Jain,V., Singh, D., Saraf, S. and Saraf, S. (2003). In-vitro micropropagation of Rauwolfia serpentina through multiple shoot generation. Ancient science of life, Xxiii (1):1-5.

Mallick, S. R., Jena, R. C. and Samal, S. C.(2012). Rapid in Vitro multiplication of an endangered medicinal plant sarpgandha (Rauwolfia serpentina). American Journal of Plant Sciences, 3:437-442.

Mitra,G. C.(1976).Studies on the formation of viable and non -viable seeds in Rauwolfia serpentina Benth. Indian Journal of Experimental Biology, 14(1):54-56.

Panwar, G. S., Attitalla, I. H. and Guru, S. K. (2011). An efficient in vitro clonal propagation and estimation of reserpine content in different plant parts of Rauwolfia serpentina. American Eurasian Journal of Scientific Research ,6 (4) : 217-222.
Prakash, P. (2001). Indian medicinal plants, Forgotten Healers. A Guide to Ayurvedic Herbal Medicine, 229-230.

Rahman, M. S. M., Islam, S., Haque, N., Jubair, T. A., Haque, A. K. M. F. and Mukti, I. J. (2008). The influence of different hormone concentration and combination on callus induction and regeneration of Rauwolfia serpentina L.," Benth. Pakistan Journal of Biological Sciences, 11 (12): 1638-1641.

Rani, A., Kumar, M. and Kumar, S. (2013). Rapid in vitro propagation of Serpagandha (Rauvolfia serpentina Lin.) Benth through young leaves. Advances of Applied Research, 5(2): 131-134.

Singh, P., Arvind, K. S., Lalitsingh, V.P. and Tapan, K.N. (2009). Somatic embryogenesis and In vitro regeneration of an endangered medicinal plant Sarpagandha (Rauvolfia serpentina L). Researcher, 1(3) : 46-53.

Susila, T., Reddy, G. S. and Jyothsna, D. (2013). Standardization of protocol for in vitro propagation of an endangered medicinal plant Rauwolfia serpentina Benth. Journal of Medicinal Plants Research,7(29): 2150-2153. 